\title{
Modeling of Human Driving Behavior Based on Piecewise Linear Model
}

UDK 004.94:656.05

IFAC 5.7.1

Original scientific paper

\begin{abstract}
This paper presents development of the modeling strategy of the human driving behavior based on the expression as Piecewise Linear (PWL) model focusing on the driver's stopping maneuver. The driving data are collected by using the three-dimensional driving simulator based on CAVE Automatic Virtual Environment (CAVE), which provides stereoscopic immersive virtual environment. In our modeling, the control scenario of the human driver, that is, the mapping from the driver's sensory information to the operation of the driver such as acceleration, braking and steering, is expressed by Piecewise Linear (PWL) model. Since the PWL model includes both continuous behaviors given by polynomials and discrete logical conditions, it can be regarded as a class of Hybrid Dynamical System (HDS). The identification problem for the PWL model is formulated as the Mixed Integer Linear Programming (MILP) by transforming the switching conditions into binary variables. From the obtained results, it is found that the driver appropriately switches the 'control law' according to the sensory information. These results enable us to capture not only the physical meaning of the driving skill, but also the decision-making aspect (switching conditions) in the driver's stopping maneuver.
\end{abstract}

Key words: human driving, piecewise linear model, driving simulator, identification

\section{INTRODUCTION}

Recently, the modeling of driving behavior has attracted great attention by many researchers $[1,2$, $3,4,5,6]$, and this will also play an essential role in the design of a secure and safe vehicle operating system. Since the human driving behavior can be considered as a mapping from driver's sensory information to the operations of driver such as acceleration, braking and steering, some linear controller models have been proposed [7, 8, 9]. Although the linear models enable us to capture the physical characteristics of the driving behavior intuitively, they sometimes mislead us to wrong understanding due to the high nonlinearity included in the human driving behavior. This tendency would be emphasized when the considered task becomes complex. In order to obtain more sophisticated driver model, some nonlinear dynamics based modeling is promising [10]. From this viewpoint, the Hidden Markov Models (HMMs), the nonlinear regression models, the neural networks and the fuzzy systems have been used [11, 12, 13, 14, 15]. These techniques, however, have some problems as follows: (1) the obtained model often results in too complicated model, (2) this makes it impossible to understand the physical meaning of the driving behavior and (3) the usefulness of information ob- tained by these models also remains questionable especially for the design of driving assistance system based on the driver model. When we look at the driving behavior, it is often found that the driver appropriately switches the simple control laws instead of adopting the complex nonlinear control law. The switching mechanism can be regarded as a kind of driver's decision-making in the driving behavior. Therefore, it is highly recommended that the model of the driving behavior involve both physical skill (operation) and the decision-making aspect (switching condition). This kind of expression can be categorized into a class of Hybrid Dynamical System (HDS). HDSs are systems, which consist of both continuous dynamics and logical conditions. The former are typically associated with the differential (or difference) equations, the latter with combinatorial logics, automata and so on. Although many literatures have dealt with the expression, stability analysis, control, verification and identification of the HDS in the control and computer science communities [16], the application of the HDS model to the analysis of the human behavior has not been fully discussed yet. In this paper, the Piecewise Linear (PWL) model, which is a class of the HDS, is adopted to understand the human driving behavior especially focusing on the driver's 
stopping maneuver. The driving data are collected by using the three-dimensional Driving Simulator (DS) based on CAVE, which provides stereoscopic immersive vision. Although our DS does not have motion generator, thanks to the effect of the stereoscopic immersive vision, the examinee can feel the pseudo-acceleration. The advantages of using DS are (1) The safety of the examinee is always guaranteed, and (2) All environmental information can be captured without installing any sensor. In our modeling, the relationship between the driver's sensory information such as distance to the stop line, its first and second derivatives, and the output of the driver such as the braking amount are expressed by the PWL model. Then, we formulate the identification problem for the PWL model as the Mixed Integer Linear Programming (MILP) by transforming the logical conditions into inequalities $[17,18,19]$. By applying the developed strategy, it becomes possible to find not only coefficients in the polynomials but also parameters in the switching conditions from the measured driving data. This implies that both physical meaning of the driving skill and the decision-making aspect (switching condition) in the driving behavior can be identified simultaneously.

This paper is organized as follows. In Section 2, configuration of the developed DS based on the CAVE is introduced. In Section 3, the scenario of our examination is described. Based on the setup described in Section 3, driver's stopping maneuvers are investigated in Section 4. In Section 5, the modeling of the stopping maneuver based on the expression as the PWL model is introduced, and identification results based on the MILP are shown.

\section{CONFIGURATION OF DRIVING SIMULATOR}

The configuration and appearance of the developed DS based on the CAVE are showning in Figures 1(a) and (b). The display unit in the CAVE system provides the $3 \mathrm{D}$ virtual environment, and it is controlled by ONYX2 (ONYX2-IR2 Desk Side). The display program was developed by making use of the CAVE library and the Performer. The cockpit is built by installing a real steering wheel, an accelerator and a brake in the CAVE system. The information on the driver's output to the steering wheel, accelerator and brake is transferred to the PC through the USB terminal, and the vehicle position and motion are calculated based on these inputs and vehicle dynamics implemented on the PC using the CarSim software. The results of the calculation are transferred to ONYX2 through the Internet (TCP/IP), and the 3D visual image based on the position and motion of the vehicle is displayed.

\section{CAPTURING DRIVING BEHAVIOR}

\section{A. Road environment and investigated task}

Generally speaking, most traffic accidents occur at intersections [9]. In this paper, we focus on a stopping maneuver in front of the stop line because this maneuver strongly depends on the distance to the stop line, and our DS has clear advantage over other 2D virtual environment based DS [2].

In order to model the stopping maneuver, the following sensory information is captured as the inputs:

(i) Distance from the front end of the vehicle to the stop line $\left[x_{1, k}\right]$

(ii) First time derivative of (i) (velocity) $\left[x_{2, k}\right]$

(iii) Second time derivative of (i) (acceleration) $\left[x_{3, k}\right]$

The outputs of the driver are also specified as follows:

(i) Acceleration output $\left[y_{1, k}\right]$

(ii) Brake output $\left[y_{2, k}\right]$.

Note that no steering operation is necessary in the stopping maneuver.

Since it is reported that the acceleration $x_{3, k}$ has less importance in the stopping maneuver [2], (i) and (ii) of the sensory information and (ii) of the output of the driver are used for the modeling.

The configuration of the intersection and its projected image are shown in Figures 2(a) and (b) with some geometric parameters.

The road is $7 \mathrm{~m}$ wide and the pedestrian way is $2 \mathrm{~m}$ wide. There are two intersections in this environment (A and $\mathrm{B}$ ). The driver is supposed to stop in front of the stop line at the intersection (A). The vehicle is supposed to start moving at position (a or b).

\section{B. Driving conditions}

The vehicle used in the simulator is a large-size passenger car whose engine displacement is 3000 cc. The bonnet of the vehicle can be seen from the driver. Eight male drivers who have driver's licences, ranging in age from 22 to 25 years, are selected as examinees. All examinees did not know the purpose of this experiment and we did not allow them to have any knowledge regarding this study. They also had never driven on the simulator before. The maximum velocity is set to be $50 \mathrm{~km} / \mathrm{h}$, and the selected starting point is $0 \mathrm{~m}$ or $100 \mathrm{~m}$ as shown in Figure 2(a). Each driver takes a number of preliminary trials to get used to the DS, and then begins the test, which is made up of numerous trials. The number of trials for each driver is listed in Table 1. 

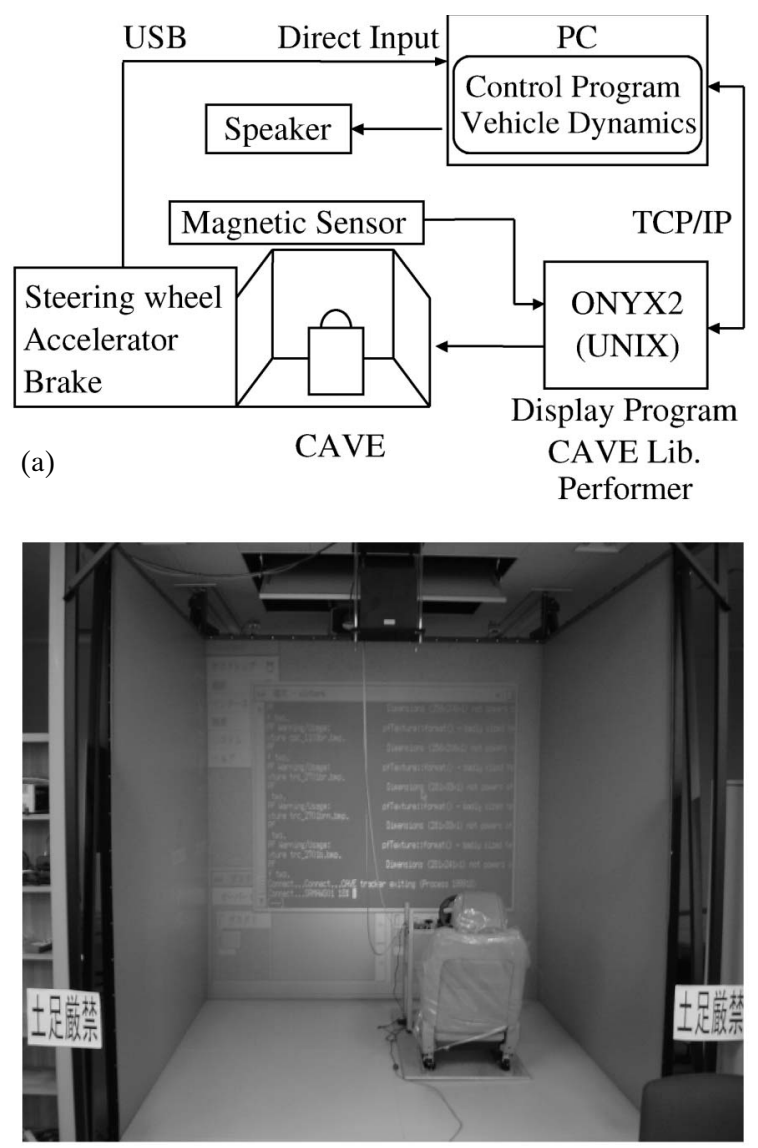

(b)

Fig. 1 The developed driving simulator. (a) Configuration of the $D S$, (b) CAVE system

Table 1 Experimental conditions

\begin{tabular}{|l|c|c|}
\hline \multirow{2}{*}{ Notation } & \multicolumn{2}{|c|}{$\begin{array}{c}\text { Driving conditions (Maximum steady } \\
\text { running velocity }[\mathrm{km} / \mathrm{h}] \text {, start point }[\mathrm{m}] \text { ) }\end{array}$} \\
\cline { 2 - 3 } & $50 \mathrm{~km} / \mathrm{h} 0 \mathrm{~m}$ & $50 \mathrm{~km} / \mathrm{h} 100 \mathrm{~m}$ \\
\hline Preliminary drive & Ten times & Ten times \\
\hline Test drive & Three times & Three times \\
\hline
\end{tabular}

\section{Experimental procedures}

Both preliminary trials and test trials are carried out twenty times and six times, respectively. These trials consist of two different driving situations:

(1) Velocity restriction of $50 \mathrm{~km} / \mathrm{h}$, starting point of $0 \mathrm{~m}$.

(2) Velocity restriction of $50 \mathrm{~km} / \mathrm{h}$, starting point of $100 \mathrm{~m}$.

The experiments are executed in the sequence shown in Table 1. After the preliminary trials, the driver rests for 10 minutes, and answers a questionnaire in which he record his impressions of his driving behavior, driving preferences, SSQ [20], and so on. The SSQ schedule is a way to find a driver
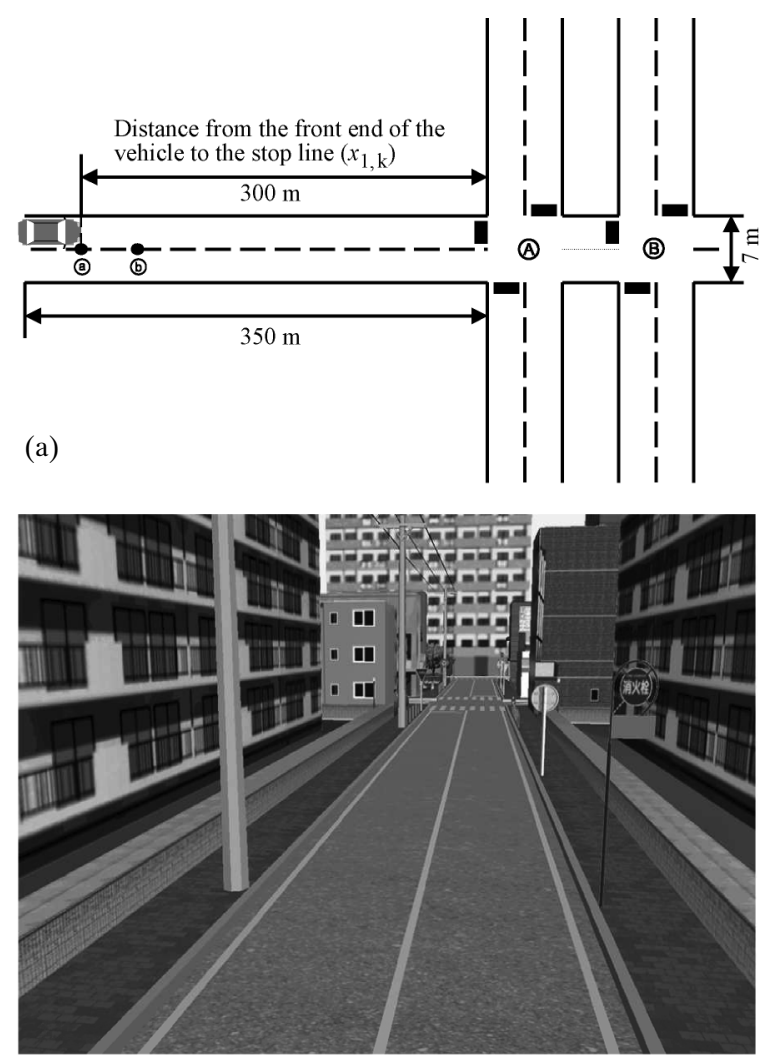

(b)

Fig. 2 Approaching an intersection. (a) Model of intersection. (b) Sample of projected image

who is likely to suffer from simulator sickness. If the driver wants to quit the experiment due to the simulator sickness, the experiment is suspended. Each driver takes about 30 minutes to complete all of the trials.

\section{EXPERIMENTAL RESULTS AND PROPOSED MODELING FRAMEWORK}

Based on the setup described in section III, eight drivers carried out the experiment under virtual environments.

Firstly, the stopping maneuver, which is characterized by the profile between the beginning of the deceleration and the stopping point, were measured and analyzed. The profiles of the driving data of the six drivers in the case that the velocity restriction is $50 \mathrm{~km} / \mathrm{h}$ are depicted in Figure 3 (the data of third and fourth trials with $50 \mathrm{~km} / \mathrm{h}, 0 \mathrm{~m}$ and 50 $\mathrm{km} / \mathrm{h}, 100 \mathrm{~m}$, respectively).

The data of the driver who has shown high levels of simulator sickness in our questionnaires were not used for the modeling. The personal information of six examinees are listed in Table 2. 

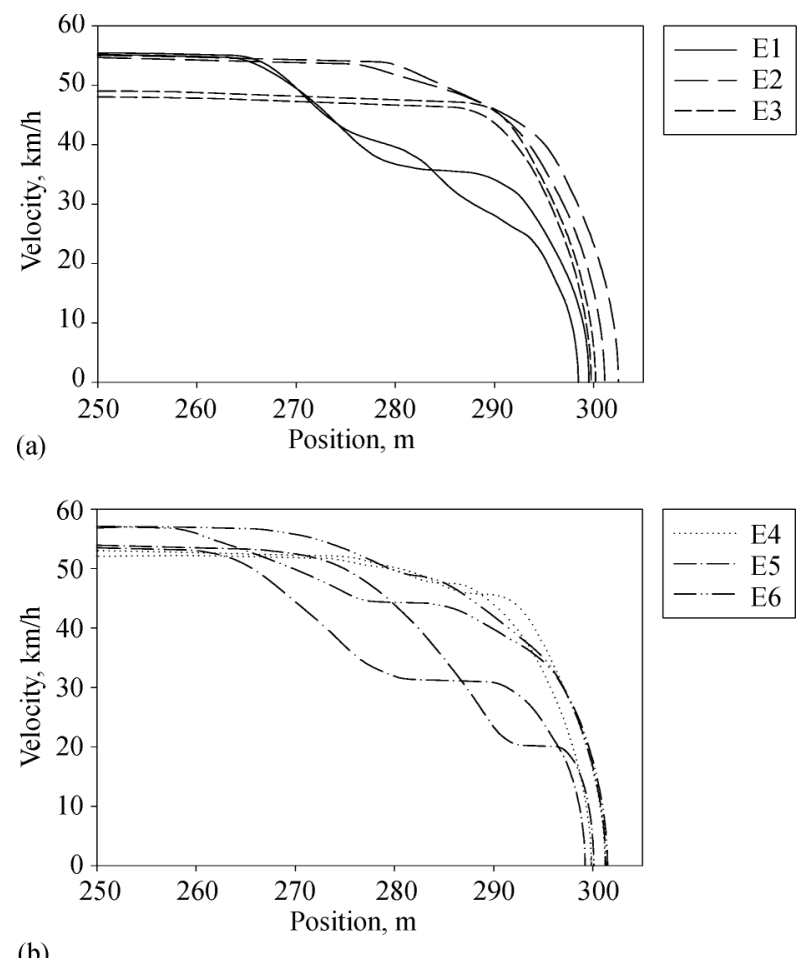

(b)

Fig. 3 Behavior at stoping

The horizontal and vertical axes in Figure 3 denote the position (stop line is located at $300 \mathrm{~m}$ ) and the velocity of the vehicle, respectively. When we look at profiles in Figure 3, roughly speaking, the stopping maneuver can be regarded as the series of the following three sub-maneuvers: (1) deceleration, (2) running with constant velocity and (3) re-deceleration. This sequence of sub-maneuvers is often observed in the driving pattern in real cars. In Figure 3(a), however, the drivers E2 and E3 show different maneuver from one described above. From the answer to the questionnaire, we could find the reason of this as follows: The driver (E2) often makes »sudden stopping « in his real driving situation. Also, the driver (E3) has found the optimal beginning point for the deceleration by investigating the building and the electric pole around the stop line instead of taking a look at the stop line in this experiment.

Table 2 Individual information of Examinees

\begin{tabular}{|c|c|c|c|}
\hline Examinee & $\begin{array}{c}\text { Age } \\
\text { Years old }\end{array}$ & $\begin{array}{c}\text { Mileage per year } \\
\mathrm{km}\end{array}$ & $\begin{array}{c}\text { Driving Career } \\
\text { Years }\end{array}$ \\
\hline E1 & 22 & 2500 & 3 \\
\hline E2 & 22 & 15000 & 2 \\
\hline E3 & 21 & 5000 & 3 \\
\hline E4 & 22 & 5000 & 4 \\
\hline E5 & 22 & 5000 & 3 \\
\hline E6 & 22 & 25000 & 3 \\
\hline
\end{tabular}

In the following, we call the duration corresponding to above three sub-maneuvers »Interval $\mathrm{A}$ «, »Interval $\mathrm{B}$ « and »Interval $\mathrm{C} \ll$.

The more formal expression based on the polynomial model is introduced in the following.

The interval $A$ (deceleration)

$$
\begin{gathered}
y_{2, k+1}=a_{0} x_{1, k}+a_{1} x_{2, k}+a_{2} x_{1, k}^{2}+a_{3} x_{2, k}^{2} \\
\text { if } \quad d_{2}>x_{1, k}
\end{gathered}
$$

The interval B (running with constant velocity)

$$
\begin{gathered}
y_{2, k+1}=b_{0} x_{1, k}+b_{1} x_{2, k}+b_{2} x_{1, k}^{2}+b_{3} x_{2, k}^{2} \\
\text { if } \quad d_{2}>x_{1, k} \geq d_{1}
\end{gathered}
$$

The interval $C$ (re-deceleration)

$$
\begin{gathered}
y_{2, k+1}=c_{0} x_{1, k}+c_{1} x_{2, k}+c_{2} x_{1, k}^{2}+c_{3} x_{2, k}^{2} \\
\text { if } \quad x_{1, k} \geq d_{2}
\end{gathered}
$$

where, the time lap between $k$ and $k+1$ is $200 \mathrm{~ms}$. Note that our model in the continuous part represents a static mapping from the sensory information to the steering operation, the main reason of this is to reduce the computational burden required for the MILP. However, the PWL model can easily include the dynamics in the continuous part by introducing the Autoregressive (AR) model. The same formulation is also available in this case.

Also, the graphic representation of this behavior, which is based on Hybrid Automaton (HA) expression is depicted by Figure 4 .

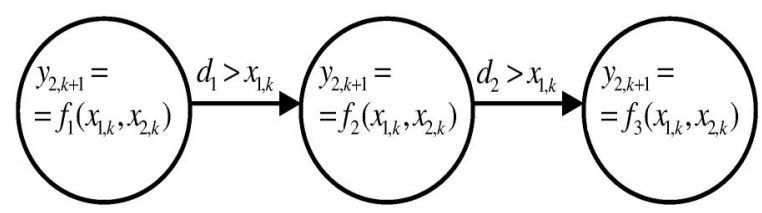

Fig. 4 Graphical representation of PWL model

In eqs. 1 to $3, x_{1, k}$ and $x_{2, k}$ denote the position and velocity, respectively. $d_{1}$ and $d_{2}$ are parameters to specify the switching between intervals. Note that only $x_{1, k}$ and $x_{2, k}$ appear in the right-hand side in eqs. 1 to 3 . In our study [2], we have clarified that $x_{1, k}$ and $x_{2, k}$ play important roles in the stopping maneuver by applying the GMDH technique. Also, the number of switching may be reduced to explain the behavior found in examinees E2 and E3. This behavior, however, can be explained naturally by setting the distance between $d_{1}$ and $d_{2}$ to be small. Since the structure of this model contains both the continuous dynamics (polynomials) and the logical conditions (switching of polynomials), the proposed model belongs to a kind of Hybrid Dynamical Systems (HDS). 
As alternative ways of modeling the driving behavior, for example, nonlinear regression models, neural network and fuzzy system can be used. If we use these techniques, however, the obtained model often results in too complicated model, and this makes it impossible to understand the physical meaning of the driver's behavior. On the contrary, the HDS model proposed in this section enables us to capture not only the physical meaning (polynomials), but also the decision-making aspect (logical conditions) in the driving behavior. Note that the switching conditions between each interval are not specified in advance in our model. The parameter specifying switching condition $\left(d_{1}\right.$ and $\left.d_{2}\right)$ and coefficients appearing in each polynomial $\left(a_{i}\right.$ to $\left.c_{i}\right)$ must be found simultaneously from the measured data. In the next section, the strategy to solve this simultaneous identification problem is developed.

\section{MODELING OF DRIVER'S BEHAVIOR BASED ON PWL EXPRESSION}

A. Expression as Piece-Wise Linear Model (PWL)

PWL is one of classes of hybrid system, in which logic, dynamics and constraints are integrated. PWL is formulated by (4).

$$
y_{2, k+1}=\left\{\begin{array}{c}
a_{0} x_{1, k}+a_{1} x_{2, k}+a_{2} x_{1, k}^{2}+a_{3} x_{2, k}^{2} \\
\text { if } d_{1}>x_{1, k} \\
b_{0} x_{1, k}+b_{1} x_{2, k}+b_{2} x_{1, k}^{2}+b_{3} x_{2, k}^{2} \\
\text { if } d_{2}>x_{1, k} \geq d_{1} \\
c_{0} x_{1, k}+c_{1} x_{2, k}+c_{2} x_{1, k}^{2}+c_{3} x_{2, k}^{2} \\
\text { if } x_{1, k} \geq d_{2}
\end{array}\right.
$$

where $k \in Z$ is a discrete time. Thus, the PWL form includes both continuous dynamics (polynomials) and logical conditions. The goal of our modeling is to find not only coefficients in the polynomials $a_{i}$, $b_{i}$ and $c_{i}$ but also parameters in the $»$ switching conditions « $d_{i}$ from the measured driving data. Although this identification problem is not straightforward to handle, the idea developed in the Mixed Logical Dynamical Systems framework [17, 18] makes it tractable. The key idea is to transform the logical condition into some inequalities by introducing auxiliary binary variables $\delta \in\{0,1\}$ and auxiliary continuous variables $z$, and to formulate the problem as the Mixed Integer Linear Programming.

\section{B. Useful tools for transformation from logical condition into inequalities}

In this section, some useful tools to transform the logical condition into inequalities are introduced. Firstly, the logical relationship given by

$$
[f(x) \geq a] \Leftrightarrow[\delta=1]
$$

can be transformed into inequalities (6) and (7).

$$
\begin{gathered}
-f(x)+(a-m) \delta+m \leq 0 \\
f(x)-(M-a+\varepsilon) \delta-a+\varepsilon \leq 0
\end{gathered}
$$

where $M=\max _{x} f(x), m=\min _{x} f(x)$, and $\varepsilon>0$ is a small tolerance. Also, in our setup, the product term of binary and continuous variables such as $\delta f(x)$ often appear. Since it is undesirable to handle this nonlinear term, we secondly introduce another auxiliary variable $z=\delta f(x)$, which satisfies the following two logical relationships.

$$
[\delta=0] \Rightarrow[z=0],[\delta=1] \Rightarrow[z=f(x)] .
$$

These relationships can be transformed into the following equivalent inequalities.

$$
\begin{gathered}
z \leq M \delta \\
-z \leq-m \delta \\
z \leq f(x)-m(1-\delta) \\
-z \leq-f(x)+M(1-\delta) .
\end{gathered}
$$

\section{Identification of PWL model by Mixed Integer Linear Programming (MILP)}

In order to transform the three logical conditions involved in (4) into the equivalent inequalities, binary variables $\delta_{1, \mathrm{k}}, \delta_{2, \mathrm{k}}$ are introduced as follows:

(1) $\left[d_{1}>x_{1, k}\right] \Leftrightarrow\left[\delta_{1, k}=0, \delta_{2, k}=0\right]$

(2) $\left[d_{2}>x_{1, k} \geq d_{1}\right] \Leftrightarrow\left[\delta_{1, k}=1, \delta_{2, k}=0\right]$

(3) $\left[x_{1, k}>d_{2}\right] \Leftrightarrow\left[\delta_{1, k}=0, \delta_{2, k}=1\right]$.

By applying the transformation rules and introducing the auxiliary variables, eq. (4) can be reformulated by the following linear equation.

$$
\begin{aligned}
& y_{2, k+1}=a_{0} x_{1, k}+a_{1} x_{2, k}+a_{2} x_{1, k}^{2}+a_{3} x_{2, k}^{2}+ \\
& +x_{1, k} z_{1, k}+x_{2, k} z_{2, k}+x_{1, k}^{2} z_{3, k}+x_{2, k}^{2} z_{4, k}+ \\
& +x_{1, k} z_{5, k}+x_{2, k} z_{6, k}+x_{1, k}^{2} z_{7, k}+x_{2, k}^{2} z_{8, k}
\end{aligned}
$$

where, the auxiliary variables, $z_{i, k}$, are defined as follows:

$$
\begin{aligned}
& z_{i, k}=\delta_{1, k} f_{i, k}=\delta_{1, k}\left(b_{i-1}-a_{i-1}\right) \quad(i=1 \square 4) \\
& z_{i, k}=\delta_{2, k} f_{i, k}=\delta_{2, k}\left(c_{i-5}-a_{i-5}\right) \quad(i=5 \square 8) \\
& z_{i, k}=\delta_{1, k} f_{i, k}=\delta_{1, k} d_{i-8} \quad(i=9 \sim 10) \\
& z_{i, k}=\delta_{2, k} f_{i, k}=\delta_{2, k} d_{i-10} \quad(i=11 \square 12) .
\end{aligned}
$$

Also, as stated in the previous section, some linear inequalities that come up with the introduction of $\delta_{1, \mathrm{k}}, \delta_{2, \mathrm{k}}$ and $z_{i, k}$ must be accompanied with (13) to $(17)$. 
Now, the problem to find the parameters in the switching condition and coefficients in the polynomials is formulated as the following MILP.

$$
\begin{array}{r}
\text { known } y_{2, k+1}, x_{1, k}, x_{2, k} \\
\text { find }\left\{a_{0}, a_{1}, a_{2}, a_{3}, b_{0}, b_{1}, b_{2}, b_{3},\right. \\
\left.c_{0}, c_{1}, c_{2}, c_{3}, d_{1}, d_{2}, \delta_{1, k}, \delta_{2, k}\right\} \\
\text { which minimize } J=\sum_{k=1}^{N}\left|y_{2, k+1}-\hat{y}_{2, k+1}\right|
\end{array}
$$

subject to

$$
\begin{aligned}
& z_{i, k} \leq M_{i} \delta_{j, k} \\
& -z_{i, k} \leq-m_{i} \delta_{j, k} \\
& z_{i, k} \leq f_{i, k}-\left(1-\delta_{j, k}\right) m_{i} \\
& -z_{i, k} \leq-f_{i, k}+\left(1-\delta_{j, k}\right) M_{i} \\
& \delta_{1, k}=\{0,1\} \\
& \delta_{2, k}=\{0,1\} \\
& 0 \leq \delta_{1, k}+\delta_{2, k} \leq 1 \\
& \delta_{2, k} \leq \delta_{2, k+1} \\
& x_{1, k} \leq d_{1}-z_{9, k}+z_{10, k}+z_{11, k}-\varepsilon+\delta_{2, k}\left(M_{d}+\varepsilon\right) \\
& x_{1, k} \geq\left(1-\left(\delta_{1, k}+\delta_{2, k}\right)\right) m_{d}+z_{9, k}+z_{12, k} \\
& \hat{y}_{2, k+1}=a_{0} x_{1, k}+a_{1} x_{2, k}+a_{2} x_{1, k}^{2}+a_{3} x_{2, k}^{2}+ \\
& +x_{1, k} z_{1, k}+x_{2, k} z_{2, k}+x_{1, k}^{2} z_{3, k}+x_{2, k}^{2} z_{4, k}+ \\
& +x_{1, k} z_{5, k}+x_{2, k} z_{6, k}+x_{1, k}^{2} z_{7, k}+x_{2, k}^{2} z_{8, k}
\end{aligned}
$$

where, $M_{i}$ and $m_{i}(i=1 \sim 12)$ are the maximum and minimum values of $z_{i, k}$, and $M_{d}$ and $m_{d}$ represent the maximum and minimum values of $d_{1}$ and $d_{2}$, respectively, $\varepsilon$ is a small tolerance.

Here, we have used the performance index $\mathbf{J}$ in equation (18), and not the root mean square errors. The reason is to formulate the problem as Mixed Integer Linear Programming (MILP). If we adopt root mean square errors, the identification problem leads to Mixed Integer Quadratic Programming (MIQP). MILP has much computational advantage compared to MIQP.

There are several ways to solve the MILP. One of the most efficient algorithms is a branch-and-bound method. Although it requires some heuristic rules in the decision of the branching variable, it can guarantee the optimality, and can reduce the computational burden with assistance of appropriate heuristic rules.

Note that the computational burden strongly depends on the number of binary variables since this specifies the size of the search space. In our case, the number of the measurement points affects the computational burden significantly.

\section{Identification results of stopping maneuver based on PWL model}

Based on the formulation of the identification of the PWL model described in the previous section, the identification of parameters in the switching conditions and coefficients in the polynomials in the stopping maneuver is carried out. The profile between the beginning of the deceleration and the final stopping point of each driver shown in Figure 3 was used for the modeling.

The fifteen sampling data of the third trial of six drivers were used for the identification of the stopping maneuver. These data were selected by culling from the measured data between the beginning of the deceleration and the final stopping point. Before applying the MILP to the measured data, the input and output data were normalized as follows:

$$
\begin{gathered}
\bar{x}_{i}= \begin{cases}\frac{x_{i}}{x_{i \max }} \quad\left(x_{i} \geq 0\right) \\
-\frac{x_{i}}{x_{i \min }} \quad\left(x_{i}<0\right)\end{cases} \\
x_{i} \in\left[\begin{array}{ll}
\left.x_{i \min } x_{i \max }\right] \\
\bar{y}_{i+20}= \begin{cases}\frac{y_{i+20}}{y_{(i+20) \max }} & \left(y_{i+20} \geq 0\right) \\
-\frac{y_{i+20}}{y_{(i+20) \min }} & \left(y_{i+20}<0\right)\end{cases} \\
y_{i+20} \in\left[y_{(i+20) \min } y_{(i+20) \max }\right]
\end{array}\right.
\end{gathered}
$$

where, the magnitude of the time lag 20 was specified by taking into account the time lap from the recognition to occurrence of some action in the human behavior. The existence of such time lag is widely known, and it varies from $100 \mathrm{~ms}$ to $300 \mathrm{~ms}$ in ordinal case [21]. Therefore, we have decided to adopt the above relationship by taking into account the sampling interval $10 \mathrm{~ms}$ (i.e. $200 \mathrm{~ms}$ time lap) in our experiment. All numerical experiments have been performed by PC (CPU $43.06 \mathrm{GHz}$ and Memory $1024 \mathrm{MB}$ ). We have used commercial software called NUOPT to solve MILP. It took about five minutes to find the solution for each trial data. In order to verify the validity of the obtained PWL model, the reproduced braking amount, which is calculated using the MILP, and the measured braking amount and the velocity of the vehicle are plotted in Figure 5. In Figure 5, the horizontal axis represents the distance from the starting point. The left and right side vertical axes represent the velo- 


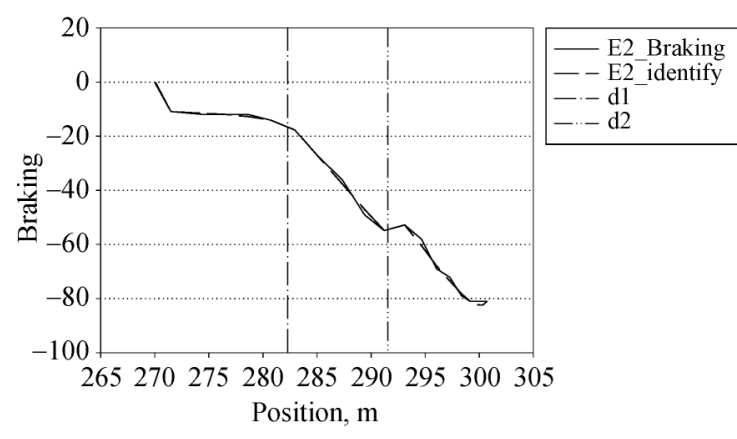

(a)

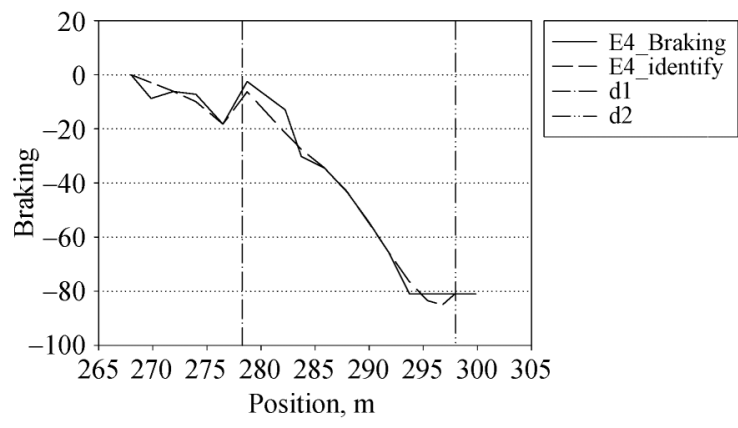

(b)

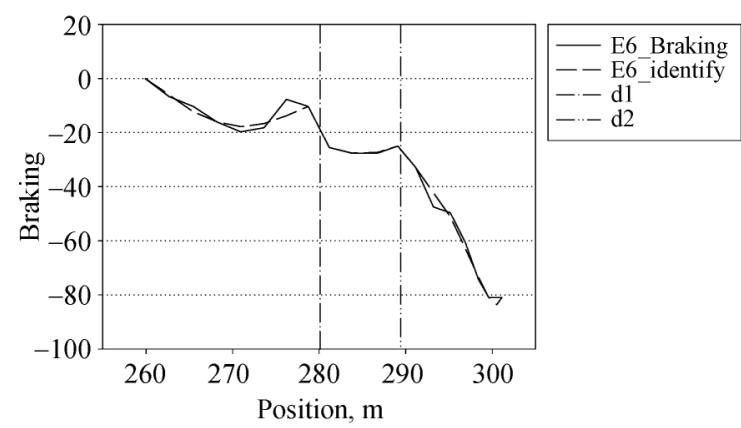

(c)

Fig. 5 Comparision of actual brake output and estimated brake output

city and braking amount of the vehicle, respectively. The stopping line is located at $300 \mathrm{~m}$. Note that the braking amount takes negative values, and zero braking implies »no braking «. Also, the switching points between polynomials are designated by vertical lines. As shown in Figure 5, the measured braking amount and reproduced braking amount based on the PWL model agree well with each other. These results verify the effectiveness of the modeling based on the PWL. It is interesting that the switching points, however, vary from driver to driver. In order to understand the common characteristics in the stopping maneuver, the identified parameters for three examinees (E2, E4 and E6) by solving the MILP are listed in Table 3 .
Table 3 Identified parameters and values by a PWL form of E2, E4 and E6

\begin{tabular}{|c|c|c|c|}
\hline Parameters & Values (E2) & Values (E4) & Values (E6) \\
\hline$\underline{\mathrm{a}}_{0}$ & $\underline{-20.0000}$ & $\underline{-11.9998}$ & $\underline{6.4176}$ \\
\hline$\underline{\mathrm{a}}_{1}$ & $\underline{18.4967}$ & $\underline{11.0857}$ & $\underline{7.2829}$ \\
\hline$\underline{\mathrm{a}}_{2}$ & $\underline{10.5879}$ & $\underline{3.9591}$ & $\underline{-9.0000}$ \\
\hline$\underline{\mathrm{a}}_{3}$ & $\underline{-9.2047}$ & $\underline{-3.5232}$ & $\underline{-6.1172}$ \\
\hline$\underline{\mathrm{b}}_{0}$ & $\underline{21.4997}$ & $\underline{11.8071}$ & $\underline{9.0015}$ \\
\hline $\mathrm{b}_{1}$ & -13.4830 & -3.3074 & -4.5481 \\
\hline$\underline{\mathrm{b}}_{2}$ & $\underline{-12.0000}$ & $\underline{-34.4040}$ & $\underline{-7.2462}$ \\
\hline $\mathrm{b}_{3}$ & 8.4156 & -2.6886 & 2.0438 \\
\hline$\underline{\mathrm{c}}_{0}$ & $\underline{-22.4999}$ & $\underline{-1.9027}$ & $\underline{-9.0017}$ \\
\hline $\mathrm{c}_{1}$ & -0.8727 & -0.0000 & -1.6208 \\
\hline$\underline{\mathrm{c}}_{2}$ & $\underline{21.5758}$ & $\underline{0.9027}$ & $\underline{8.1642}$ \\
\hline $\mathrm{c}_{3}$ & 2.5017 & 0.0046 & 3.5966 \\
\hline $\mathrm{d}_{1}$ & 282.286 & 278.268 & 280.098 \\
\hline $\mathrm{d}_{2}$ & 291.550 & 297.986 & 289.433 \\
\hline
\end{tabular}

The coefficients in the polynomials $a_{i}, b_{i}, c_{i}$ and the parameters in the switching conditions $d_{i}$ in (13) and (18) are listed in Table 3. As shown in Table 3, the most dominant input information (designated by underline in Table 3 ) in the intervals $\mathrm{B}$ and $\mathrm{C}$ were the distance $x_{1, k}$ to the stop line, and the velocity $x_{2, k}$ did not play an important role in the stopping maneuver. On the other hand, the distance $x_{1, k}$ to the stop line and velocity $x_{2, k}$ were found to be dominant input information, and played a crucial role in the interval A. Similar tendency has been found in the identified results of other drivers.

From these observation, we can conclude that the driver appropriately switches the »control law according to the following scenario: At the beginning of the stopping maneuver (just after finding the stopping point), the driver decelerate the vehicle based on the distance to the stop line and velocity information, and then switch to another control law based on the distance to the stop line. Although the switching points depend on the driver's characteristics, qualitatively speaking, the scenario described above can be found as common characteristics in all drivers.

These results highly demonstrate the usefulness of the modeling based on the expression as an HDS.

\section{CONCLUSIONS}

In this paper, we have developed the modeling strategy of the human driving behavior based on the expression as PWL model especially focusing on the driver's stopping maneuver. The driving data was collected by using the driving simulator, which 
provides three-dimensional stereoscopic immersive virtual environment. In our modeling, the relationship between the measured information such as distance to the stop line, its first and second derivatives and the braking amount has been expressed by the PWL model, which is a class of HDS. The key idea to solve the identification problem was to formulate the problem as the MILP with replacing the switching conditions by binary variables. From the obtained results, it was found that the driver appropriately switches the »control law « according to the following scenario: At the beginning of the stopping maneuver (just after finding the stopping point), the driver decelerates the vehicle based on the distance to the stop line and velocity information, and then switches to the control law based on the distance to the stop line. Thus, our proposed approach enables us to capture not only the physical meaning of the driving skill, but also the decision-making aspect (switching conditions) in the driving behavior.

The analysis in more complicated situation, and the application of the obtained results to the design of the driving assistance system are our future works.

\section{REFERENCES}

[1] M. C. Nechyba, Y. Xu, Human Control Strategy: Abstraction, Verification and Replication. IEEE Control Systems Magazine, vol. 17, no. 5, pp. 48-61, 1997.

[2] J. H. Kim, Y. Matsui, S. Hayakawa, T. Suzuki, S. Okuma, N. Tsuchida, Acquisition and Modeling of Driving Skills by Using Three Dimensional Driving Simulator. IEICE Trans. Fundamentals, Vol. E88-A, No. 3, pp. 770-778, 2005.

[3] H. Uno, K. Hiramatsu, Aged Driver's Avoidance Capabilities in an Emergent Traffic Situation. SAEJ, Vol. 32, No. 1, 113-118, January 2001.

[4] H. Ohno, Analysis and Modeling of Human Driving Behavior Using Adaptive Cruise Control. Applied Soft Computing, Elsevier, Amsterdam, Vol. 1, Issue 3, pp. 237-243, December 2001.

[5] T. Pilutti, G. Ulsoy, Identification of Driver State for Lane-Keeping Tasks. IEEE Transactions on Systems, Man, Cybernetics-Part A: Systems and Humans, Vol. 29, No. 5, pp. 486-502, September 1999.

[6] L.-K. Chen, G. Ulsoy, Identification of a Driver Steering Model, and Model Uncertainty, From Driving Simulator Data. ASME Journal of Dynamic Systems, Measurement, and Control, Vol. 123, pp. 623-629, December 2001.
[7] K. Morita, J. Mashiko, T. Okada, A Study on Delay in Braking Operation when Drivers Looking Aside from Road Ahead. Transactions of Society of Automotive Engineers of Japan, Vol. 33, No. 3, pp. 161-166, July 2002.

[8] N. Takubo, T. Fujioka, Analysis of Glance Away in Driving. Transactions of Society of Automotive Engineers of Japan, Vol. 34, No. 2, pp. 107-112, April 2003.

[9] Y. Amano, M. Hada, S. Doi, A Model of Driver's Behavior in Ordinary and Emergent Situations. R \& D Review of Toyota CRDL, Vol. 33, No. 1, pp. 23-30, March 1998.

[10] J. Sjoberg, Q. Zhang, L. Ljung, A. Benveniste, B. Deylon, P. Y. Glorenner, H. Hjalmarsson, A. Juditsky, Nonlinear Black-Box Modeling in System Identification: a Unified Overview. Automatica, 31(12), pp. 1691-1724, 1995.

[11] A. Pentland, A. Liu, Modeling and Prediction of Human Behavior. Neural Computation 11, pp. 229-242, 1999.

[12] M. C. Nechyba, Y. Xu, On the Fidelity of Human Skill Models. Proceedings of the 1996 IEEE International Conference on Robotics and Automation, pp. 2688-2693, April 1996.

[13] N. Kuge, T. Yamamura, O. Shimoyama, A. Liu, A Driver Behavior Recognition Method Based on a Driver Model Framework. Number 2000-01-0349 in SAE Technical Paper Series, 2000.

[14] S. J. Farlow, Self-organizing Method in Modeling. Marcel Decker USA, 1984.

[15] I. Hayashi, H. Tanaka, The Fuzzy GMDH Algorithm by Possibility Models and Its Application. Fuzzy Sets and Systems 36, 245-258, 1990.

[16] O. Maler, A. Pnueli (Eds.), Lecture Notes in Computer Science, Hybrid Systems: Computation and Control, $6^{\text {th }}$ International Workshop, HSCC'03, Springer, 2003.

[17] A. Bemporad, G. Ferrari-Trecate, M. Moarari, Observability and Controllability of Piecewise Affine and Hybrid Systems. IEEE Transaction on Automatic Control, Vol. 45, No. 10, 1864-1876, October 2000.

[18] A. Bemporad, M. Moarari, Control of Systems Integration Logic, Dynamics, and Constraints. Automatica, Vol. 35, pp. 407-427, March 1999.

[19] A. Bemporad, J. Roll, L. Ljung, Identification of Hybrid Systems via Mixed-Integer Programming. Proceedings of The $40^{\text {th }}$ IEEE Conference on Decision and Control, pp. 786-792, December 2001.

[20] H. Been-Lirn Duh etc, An »Independent Visual Background« Reduced Balance Disturbance Evoked by Visual Scene Motion: Implication for Alleviating Simulator Sickness, SIGCHI'01, 4,2001, Seattle, USA.

[21] S. Inaba, Traffic Accident and Human Engineering. Books Corona JAPAN, 1988.

Modeliranje ljudske vožnje primjenom po dijelovima linearnog modela. Ovaj članak prikazuje razvoj strategije modeliranja ljudskog ponašanja pri vožnji, koja je utemeljena na po dijelovima linearnom (PWL) modelu fokusiranom na vozačev manevar zaustavljanja. Podaci o vožnji prikupljeni su korištenjem trodimenzionalnog simulatora vožnje zasnovanog na CAVE Automatic Virtual Environment (CAVE) koji osigurava potpuno stereoskopsko virtualno okruženje. Pri modeliranju je upravljački scenarij za vozača, odnosno preslikavanje vozačevih senzorskih informacija u operacije poput ubrzanja, kočenja i upravljanja vozilom, opisan PWL modelom. Kako PWL model uklju- 
čuje istodobno kontinuirano ponašanje izraženo preko polinoma kao i diskretne logičke uvjete, takav se model može promatrati kao klasa hibridnih dinamičkih sustava (HDS). Transformiranjem uvjeta prekapčanja u binarne varijable, problem identifikacije PWL modela formuliran je kao mješoviti cjelobrojni linearni program (MILP). Iz dobivenih je rezultata vidljivo da vozač prekapča »zakon upravljanja u skladu sa senzorskim informacijama. Rezultati omogućuju razumijevanje ne samo fizikalnog značenja sposobnosti vožnje već i sam aspekt donošenja odluka (uvjeta prekapčanja) prilikom vozačevog manevra zaustavljanja.

Ključne riječi: ljudska vožnja, po dijelovima linearni model, simulator vožnje, identifikacija

\section{AUTHORS' ADDRESSES}

Jong-Hae Kim

Dept. of Electrical Engineering and Computer Science, Graduate School of Engineering, Nagoya University, Japan e-mail:kimjh@okuma.nuee.nagoya-u.ac.jp, kjhassk@hanmail.net

Young-Woo Kim

Space Robotics Research Center, Toyota Technological Institute, Nagoya City, Japan

e-mail:kim@toyota-ti.ac.jp

Don-Ha Hwang

Industry Applications Research Laboratory, Korea

Electrotechnology Research Institute (KERI), Changwon, Korea e-mail: dhhwang@keri.re.kr

Received: 2005-12-01 